\title{
Safety awareness among junior psychiatrists and provisions for their safety in the workplace
}

\author{
Helen Chubb
}

\begin{abstract}
Violence in the workplace is of great concern to trainee peychiatrists. A questionnaire was devised to assess knowledge of safety issues, and precautions available, among junior doctors. The results, which revealed gaps in provision of safety training and facillites in this area, have been forwarded to the relevant directorates with a view to selting standards sultable for audit review.
\end{abstract}

Violence in the workplace is of great concern to any junior doctor who has faced a violent incident themselves or has been made aware of one through colleagues. It is more common than expected - O'Sullivan \& Meagher (1995) found that $39 \%$ of psychiatrists had been assaulted at work and $12 \%$ had sustained physical injury. As the level of violence occurring on in-patient units increases (James et al, 1990), so does the level of concern among junior doctors and this is reflected by the increase in articles published on the topic (Rosenbaum, 1991).

The Collegiate Trainees' Committee (CTC) have long been aware of this problem and have wanted to ensure that all juniors are taught how to manage a violent incident and have adequate backup. They set up a working party in 1989 and the report (CTC Working Party, 1991) made a number of recommendations. The points raised have been incorporated into the Statement on Approval of Training Schemes for General Professional Training (Royal College of Psychiatrists, 1996). If these standards are not achieved or maintained in hospitals, then training schemes may have their approval removed. The Statement was reviewed by the CTC in November 1995 and revision suggested. Moreover, the Management of Health and Safety at Work regulations (Health and Safety Executive, 1992) require hospitals to assess health and safety risks to employees, record measures resulting from this risk assessment and give adequate training so staff are capable of avoiding risks. Black \& Guthrie (1990) drew attention to the risks taken by psychiatrists when doing domiciliary visits and this is becoming more important as community psychiatry grows.
The aim of this paper is to assess the level of awareness of safety issues among junior psychiatric trainees and the precautions taken to ensure their personal safety in the workplace. Emphasis was placed on what the trainees believed was available rather than what actually was.

\section{The study}

A questionnaire was constructed using the recommendations laid down by the CTC in 1991 as a guideline. Responses were limited, giving only the choice of a positive response, a negative response or 'don't know'. At the end of the questionnaire, respondents were given the opportunity to add comments. A copy was sent to every junior psychiatric trainee working at that time in all the psychiatric hospitals in a Welsh county. This study involved three large psychiatric hospitals as well as a number of smaller outlying units.

\section{The findings}

The response rate was 19 out of $26(73 \%)$ of whom the majority (13 out of 19) were senior house officers (vocational or GP trainees). Fifty-three per cent of respondents were female. The mean length of training in psychiatry was 2.5 years and the mean length of time spent in this Health Authority 2.6 years. The responses are summarised in Table 1.

\section{Comments}

Many respondents added personal comments at the end of the questionnaire. Support was voiced for issues raised in the questionnaire, particularly the availability of personal alarms, positioning of interview rooms, furniture and panic buttons, the availability of legal advice and a nominated counsellor after an incident. One drew attention to the risks taken by pregnant doctors in violent incidents. One emphasised the concern that change is slow as individuals are 'fearful of rocking the boat'. 


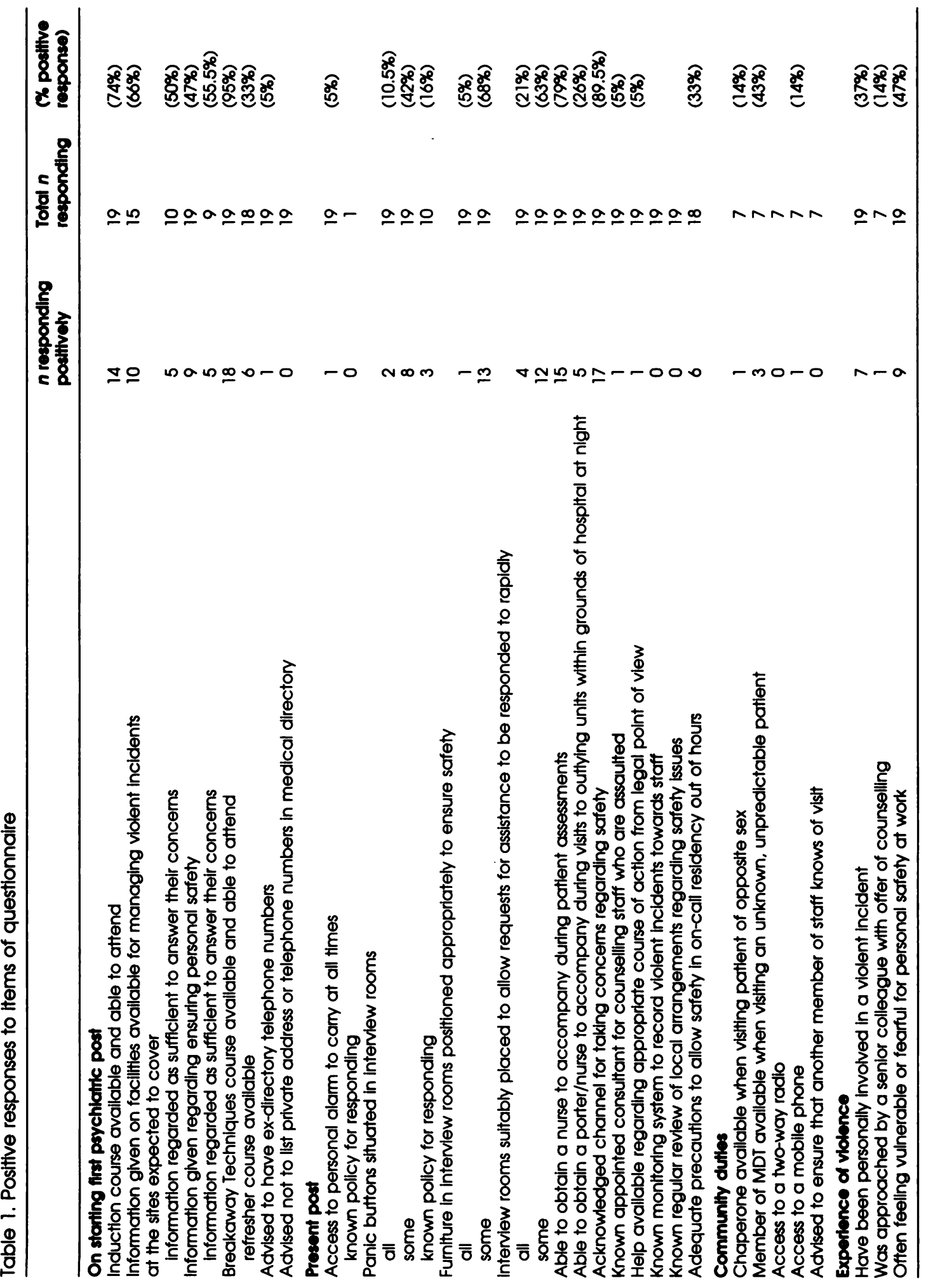




\section{Comments}

The response rate $(73 \%)$ suggests the high level of interest and concern among junior doctors regarding this issue. The frequency with which responders added extra relevant comments at the end of the questionnaire seemed to confirm this. The questionnaire, although lengthy, was straightforward and unambiguous, and hence, all respondents provided valuable figures. However, this questionnaire aims to assess the level of awareness of the availability of safety facilities rather than what is actually available, although the former might indirectly reflect the latter. To obtain details of the latter, it would be necessary to pose a similar questionnaire to the administrative teams of the Trusts and Health Authority. If a discrepancy was found, this might reflect a communication problem between the administrative levels and the junior clinical staff, rather than a lack of provision, and would need to be addressed appropriately.

The sex ratio was evenly balanced and there was no evidence to suggest that it was the female members of the group who provided the majority of the negative responses. The level of expertise was weighed towards the less experienced, i.e. SHOs and GP trainees, which reflects the usual proportions employed in general psychiatric hospitals. These juniors are the employees who are the most inexperienced in dealing with potentially violent situations. As the mean length of time in psychiatry or in this county was $\mathbf{2 . 5}$ years and 2.6 years respectively, we can be confident that respondents are reporting valuable information about what is occurring in this area.

A reassuringly high proportion of respondents had been able to attend induction courses as well as breakaway courses, which provided useful information regarding managing violent incidents. The picture changed when questions were asked regarding advice given and facilities available to prevent a violent incident occurring or escalating. Few knew of advice regarding private addresses and telephone numbers, personal alarms appeared to be rarely available and the availability of centrally placed, appropriately furnished interview rooms with carefully positioned panic buttons was limited. The questions regarding local arrangements for responding to, monitoring and reviewing assaults and violent incidents showed a very low level of awareness.

Few of those required to work in the community felt that their safety was of general concern. There was difficulty in obtaining assistance when visiting unknown and unpredictable patients and even availability of mobile phones to use in emergencies was limited to those expected to do night calls only. This will be of increasing importance as junior doctor's commitments become more community-orientated.
Perhaps most worrying was that over one-third had actually been involved in a violent incident (albeit subjectively defined), a similar figure to that found by O'Sullivan \& Meagher (1995), and almost half reported that they often felt fearful or vulnerable in the workplace.

The CTC, in November 1995, suggested a revision to the current Statement on Approval of Training Schemes for General Professional Training for MRCPsych, emphasising certain areas of concern. They recommended all trainees should have access to mobile phones and bleeps, especially when in the community; unaccompanied trainees should not be required to visit potentially dangerous patients; breakaway technique courses should be mandatory and refresher courses should be avallable; the security of the hospital environment, both in the building and in the grounds, especially in the on call accommodation, should be ensured. The findings of this questionnaire, particularly the individuals' comments, suggest that junior doctors would support these revisions to the statement.

\section{Conclusion}

This survey indicates that the county in question (involving two trusts and one health authority) was making some progress in responding to the safety concerns of their junior employees but still had some way to go in specific areas. There was an unacceptably high level of trainees being subjected to violent incidents and, when it occurs, the trainees were not aware of the channels available for them to seek help. Many were still fearful for their safety.

There appear to be gaps in the provisions for safety of junior doctors according to the recommendations of the CTC and the Standards for approval for training schemes, and these need to be addressed. These figures have been presented to the Clinical Directors of each directorate for further discussion, with a view to possibly setting up standards suitable for audit review at a later date.

This questionnaire proved a useful tool in assessing the awareness of psychiatric trainees on safety issues, and could be used in a wider setting.

\section{Acknowledgement}

I would like to thank Dr Mark Winston for his helpful and constructive comments on the text.

\section{References}

BLACK, D. \& GUTHRIE, E. (1990) Doctors' safety: who cares? British Medical Journal, 300, 1471. 
Collegiate Trainees Committee Working Party (1991) Report of the CTC Working Party on training of junior psychiatrists with respect to violent incidents. Psychiatric Bulletin, 16, 243-246.

HEALTH AND SAFETY EXECUTIVE (1992) New Health and Safety at Work Regulations. Sheffield: Health and Safety Executtve.

JAmes, D. G., Fineberg, N. A., Shah, A. K. et al (1990) An increase in violence on an acute psychiatric ward, a study of associated factors. Brttish Journal of Psychiatry. 156. 846-852.

O'Sulunan, M. \& MEAGHER, D. (1995) A three year prospective audit of assaults against psychiatrists and trainees in Dublin. Abstracts of the 1995 Winter Meeting of the Royal College of Psychiatrists.
ROSENBAUM, M. (1991) Violence in psychiatric wards, role of the lax milieu. General Hospttal Psychiatry. 13, 115-121.

RoYAl COUEGE OF PSYCHIATRISTS (1996) Statement on Approval of Training Schemes for General Professional Training. CAP/01. London: RCPsych.

Helen Chubb, Senior Registrar in Psychiatry,

South Wales Higher Professional Training Scheme, St. Tydfil's Hospital, Merthyr Tydfil, Mid Glam CF47 OSJ

\section{Nerw from Gaskell}

\section{Safeguards for Young Minds}

\section{Young People and Protective Legislation}

\section{Richard White, Richard Williams, Anthony Harbour and William Bingley}

This co-publication with the NHS Health Advisory Service is concerned with aspects of the law as it applies to the welfare and protection of minors, and the management of children and adolescents in mental health services. It includes a complete update of the Concise Guide to the Children Act 1989, with a concise summary of the provisions of the Children Act. Particular issues relating to the use of the Mental Health Act 1983 with younger people and recent developments wrought by case law are also covered. Price f10.00, 84pp., 1996, ISBN $090224194 \mathrm{X}$

Available from good bookshops and from the Publications Department, Royal College of Psychiatrists, 17 Belgrave Square, London SWIX 8PG. Credit card orders can taken over the telephone $(+44(0)$ I 7 I-235 235I, extension 146)

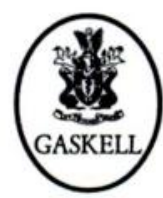

